\title{
Interactions among aerosols, clouds, and climate of the Arctic Ocean
}

\author{
Judith A. Curry \\ Program in Atmospheric and Oceanic Sciences, Department of Aerospace Engineering Sciences, Campus Box 429, \\ University of Colorado, Boulder, CO 80309, USA
}

\begin{abstract}
Considerable interest has recently been generated by the suggestion that the direct and indirect radiative effects of aerosols in the troposphere may be sufficient on a global basis to offset the radiative effects of increasing greenhouse gases. This paper focuses on understanding these relationships in the Arctic, which are of particular complexity because of the high surface albedo in the Arctic; the marked annual cycle of arctic aerosol characteristics; the extreme static stability of the arctic lower troposphere; dependence of arctic cloud infrared emissivities on drop size distribution and aerosol characteristics; sensitivity of ice nucleation to aerosols; complex radiative interactions occurring between aerosols, clouds, and sea ice; the annual cycle of aerosol residence time in the Arctic; and the impact of aerosol perturbations on the meridional heat transport to the Arctic.
\end{abstract}

Keywords: Radiative effects; Aerosols; Troposphere; Climate; Arctic Ocean

\section{Introduction}

Climate model experiments with increased $\mathrm{CO}_{2}$ concentrations have found that warming is amplified in the Arctic due to the retreat of the Arctic Ocean sea ice (IPCC, 1990; Schlesinger and Jiang, 1991). Local arctic temperature increases as large as $20^{\circ} \mathrm{C}$ during wintertime have been simulated by Wetherald and Manabe (1986) in a doubling $\mathrm{CO}_{2}$ expcriment. In the most sophisticated simulation to date of a greenhouse warming scenario with a coupled global ocean-atmosphere model, where the atmospheric carbon dioxide concentration is increased by $1 \%$ per year (compounded), Manabe et al. (1991) found a surface temperature increase of $6-7^{\circ} \mathrm{C}$ in the Arctic after 95 years of model integration. Most of the arctic temperature change occurred more than 65 years after the beginning of the $\mathrm{CO}_{2}$ increase.

Warming in the Arctic may be exacerbated as a result of the snow/ice-albedo feedback mechanism. It has been hypothesized that changes in surface albedo associated with changes in snow and ice cover as a result of temperature changes might provide significant positive feedback on climate change. This climate feedback mechanism is 
generally referred to as the 'snow/ice-albedo' feedback. As temperatures increase, the extent of snow and ice is reduced, decreasing the surface albedo and increasing the amount of sunlight that is absorbed by the Earth-atmosphere system. Conversely, a temperature decrease increases the surface albedo and thus reinforces the cooling (Curry et al. 1995). This feedback mechanism results in the Arctic having an impact on the global climate as well as the local climate, since the ice-albedo feedback mechanism can result in substantial modification of the net energy retained by the Earth-atmosphere system. The snow/ice-albedo feedback mechanism has played a prominent role in several theories of the ice ages, and is the reason that global climate models (GCMs) predict such great arctic warming in their $\mathrm{CO}_{2}$ doubling experiments.

Considerable interest has recently been generated by the studies of Charlson et al. (1992), which suggest that the direct and indirect radiative effects of aerosols in the troposphere may be sufficient on a global basis to offset the radiative effects of increasing greenhouse gases. This paper focuses on understanding these relationships in the Arctic. Will an increase in atmospheric aerosol result in a surface warming or cooling in the Arctic Ocean? Will the surface warming or cooling be great enough to alter the sea ice characteristics?

In the past two decades, it has become increasingly apparent that the Arctic is polluted (for a review, see Stonehouse, 1986; Barrie, 1986). Arctic air pollution, which is frequently referred to as 'Arctic haze', occurs mainly during the winter months. A variety of evidence indicates that the pollution originates in the mid-latitudes of the North American and Eurasian continents, with the most important transport pathways coming from Eurasia. The transport mechanisms of pollution from the mid-latitudes to the Arctic are particularly efficient during winter and spring, when the principal industrial centers are north of the polar front. Measurements from snow samples imply a $75 \%$ increase in arctic air pollution between 1952 and 1977 and show a close correlation with $\mathrm{SO}_{2}$ emissions in Europe (Barrie, 1986). Arctic pollution aerosol is composed of sulfate, organic compounds, black carbon, and trace amounts of other substances. Wintertime arctic pollution has been hypothesized to have a long residence time, which has been hypothesized to occur as a result of weak pollutant transformation and removal rates that are caused by the radiative and thermodynamic characteristics of the arctic winter troposphere.

Based on the model experiments, it appears that the Arctic should be a sensitive indicator of climate change, but observational evidence of several kinds supports the opposite point of view. For example, there is no evidence of any overall sea ice retreat over the past 15 years (Chapman and Walsh, 1993). On the inter-decadal scale, Kahl et al. (1993) report no significant trend in Arctic Ocean surface temperature over the past 40 years, in contrast to the expected response to the doubling $\mathrm{CO}_{2}$ scenario simulated by GCMs. Is it possible that the direct and indirect radiative effects of aerosols on the arctic climate are counteracting the effects of greenhouse warming? Fig. 1 shows schematically the interrelationships between aerosols, clouds, and climate; the arrows on the diagram between the components are the subject of the following discussion.

\section{Cloud-aerosol interactions}

Water vapor condenses in the atmosphere to form liquid water drops by heterogeneous nucleation on certain types of aerosol particles, particularly water-soluble particles or large particles, which are referred to as cloud condensation nuclei $(\mathrm{CCN})$. The sulfate component of the arctic pollution aerosol is a particularly good CCN. Heitzenberg et al. (1986), Shaw (1986), and Curry and Ebert (1990) have suggested that arctic pollution aerosol may modify the characteristics of $\mathrm{CCN}$ and thus modify cloud water nucleation processes in the Arctic. All other factors remaining the same, increasing amounts of $\mathrm{CCN}$ will result in a larger number of water droplets with smaller sizes. Albrecht (1989) and Twomey (1991) have further suggested that not only would drop size decrease as a result of increased $\mathrm{CCN}$, but also the total liquid water content of the cloud would increase due to decreasing efficiency of the 


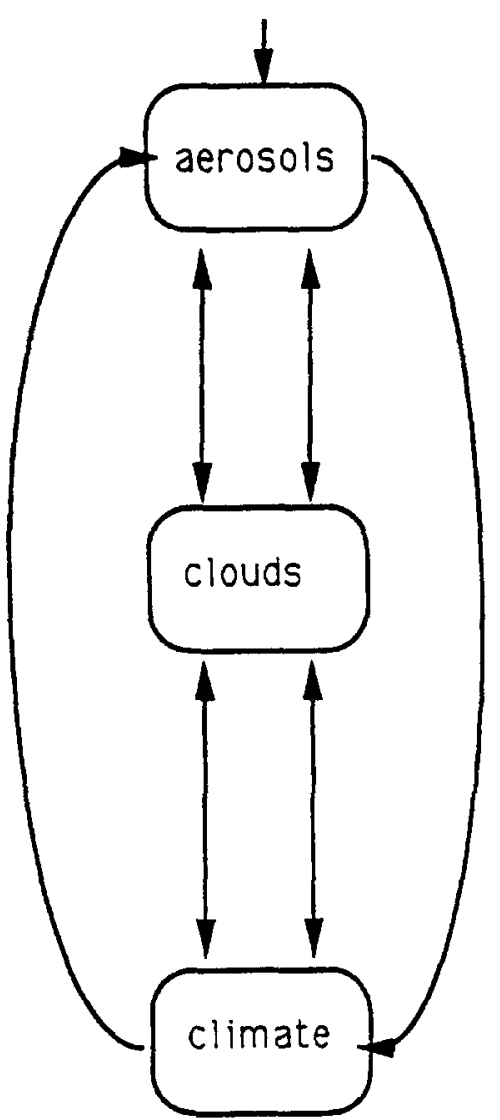

Fig. 1. Schematic diagram of aerosol-cloud-climate interactions.

precipitation process. The lifetime of an individual cloud might increase, thus increasing the areal coverage of the clouds. In assessing the impact of $\mathrm{CCN}$ on drop size distribution, one must keep in mind that cloud dynamics (particularly entrainment) influence drop size distribution as well (Telford and Wagner, 1981). However, due to the statically stable arctic environment, particularly away from the ice margin, we hypothesize here that cloud entrainment effects are of minimal importance, so that the principal determinant of drop size distribution in arctic clouds is the background air chemistry and $\mathrm{CCN}$ characteristics.

Indirect evidence for this hypothesis is given in Table 1, which presents a summary of the observed cloud microphysical properties for summertime arctic stratus. Recent measurements from the Arctic Stratus Experiment (Curry, 1986) indicate larger droplet concentrations and smaller average droplet radii than earlier measurements. Although it is possible that these differences reflect different efficiencies in measuring small drops, it is also possible that the differences between the observations reflect real differences in aerosol amount and composition. Decreasing (with time) drop sizes and increasing droplet concentrations (Table 1) may be associated with increasing anthropogenic pollution, although natural variations associated with regional and synoptic differences, as well as the seasonal phytoplankton productivity cycle, may also be factors in the variability of this limited sample.

Borys (1989), Curry et al. (1990), and Curry and Ebert (1992) have further suggested that arctic pollution aerosol may also impact ice nucleation in the Arctic. Because of the cold temperatures during the arctic winter, even the lower tropospheric clouds are predominantly crystalline (Curry et al., 1990). It has been shown generally, and in the Arctic specifically during springtime (Borys, 1983), that polluted air is typically deficient in ice-forming nuclei (IFN). This correspondence is believed to be associated with an increased amount of sulfate particles in the polluted air, which coagulate with the ice-forming

Table 1

Microphysical properties of summertime arctic clouds

\begin{tabular}{|c|c|c|c|c|c|}
\hline Reference & Date & Location & $\begin{array}{l}\text { Liquid water } \\
\text { concentration } \\
\left(\mathrm{g} / \mathrm{m}^{3}\right)\end{array}$ & $\begin{array}{l}\text { Droplet density } \\
\left(\mathrm{cm}^{3}\right)\end{array}$ & $\begin{array}{l}\text { Average drop } \\
\text { diameter } \\
(\mu \mathrm{m})\end{array}$ \\
\hline Dergach et al. (1960) & & Soviet Arctic & $0.05-0.3$ & 一 & $14-20$ \\
\hline Koptev and Voskresenskii (1962) & September 1959 & Soviet Arctic & $0.01-0.15$ & $18-91$ & 11 \\
\hline Jayaweera and Ohtake (1973) & September 1971, April 1972 & Barrow & $0.1-0.2$ & 90 & 13.5 \\
\hline Curry (1986) & June 1980 & Beaufort Sea & $0.2-0.3$ & $100-500$ & 10.4 \\
\hline
\end{tabular}


nuclei and effectively deactivate them, since sulfate particles act as poor IFN. If this is correct, ice nucleation in the Arctic may be relatively enhanced during winter, due to a decrease in the oxidation of $\mathrm{SO}_{2}^{=}$in the relative absence of sunlight and liquid water, which would result in a decreased amount of sulfate particles. Observations reported by Curry et al. (1990) during April 1983 and 1986 show that significant ice crystal nucleation seems to routinely occur at temperatures as high as -15 to $-20^{\circ} \mathrm{C}$. Earlier observations by Witte (1968) described one case with condensate that was predominantly liquid at temperatures as low as $-32^{\circ} \mathrm{C}$ during December 1967 , and Jayaweera and Ohtake (1973) found very few ice crystals at temperatures above $-20^{\circ} \mathrm{C}$ during September 1971 and April 1972. The recent observations of Curry et al. (1990) show an overall higher phase transition temperature than the earlier measurements and thus are inconsistent with the hypothesis that increasing pollution is deactivating IFN, although general conclusions cannot be drawn due to the small number of observations. In any case, the net effect of polluted air on ice nucleation in the Arctic must be regarded as uncertain, as there does not seem to be any simple relationship between sulfate concentration and the temperature at which ice nucleation occurs in the Arctic. Regardless of the exact mechanism, anthropogenic aerosol has the potential to significantly affect the amount of condensed water in the Arctic by modifying the ice nucleation and thus the phase of condensed water. Since ice crystals grow much more rapidly than liquid water drops at a given relative humidity and temperature, more water will condense if ice nucleation occurs; however the ice crystals will fall out of the atmosphere more rapidly due to their larger sizes.

In turn, clouds affect aerosols through cloud particle scavenging of aerosols and chemical reactions in clouds that increase the aerosol concentrations. The scavenging of aerosol by clouds and their removal from the atmosphere by precipitation are important sinks for atmospheric aerosol (Hegg et al., 1984). In-cloud nucleation scavenging occurs by the incorporation of $\mathrm{CCN}$ into cloud droplets by activation. In addition, aerosol particles that do not act as $\mathrm{CCN}$ can be incorporated into cloud drops through coagulation processes. As the cloud particles grow to precipitation size, they fall out of the atmosphere and thus act as a sink for atmospheric aerosol. Precipitation may also scavenge aerosol bclow the cloud base. Snow crystals are approximately twice as efficient as rain drops in scavenging aerosols.

It has often been observed that $\mathrm{CCN}$ concentrations at a given supersaturation are higher in air that has been processed by clouds than in the ambient air. Radke and Hobbs (1969) suggested that this enhancement of $\mathrm{CCN}$ activity is due to the oxidation of $\mathrm{SO}_{2}$ to form sulfate in cloud droplets. Any material formed by chemical reactions in the droplets that precipitates out of solution when the drop evaporates may either become a new aerosol particle or increase the size of an existing aerosol particle. The oxidants responsible for sulfate production in clouds include hydrogen peroxide, ozone, and oxygen.

The interactions between clouds and aerosols are illustrated in Fig. 2. An increased amount of pollution aerosol in the Arctic would increase the amount of cloud water by decreasing the production of precipitation in clouds and thus extending the cloud lifetime. An extended cloud lifetime results in an increase in $\mathrm{CCN}$ production by gasto-particle conversion processes that occur in the presence of liquid water drops. At the same time, an increase in air pollution may result in the effective deactivation of IFN, which in turn results in a decrease in ice water content, an associated decrease in the amount of ice crystal scavenging of the aerosol, and a relative increase in the amount of liquid water content. Thus, there is a positive feedback loop between aerosols and clouds, whereby a larger aerosol concentration results in increased cloud water content, which increases the cloud production of aerosols and decreases the cloud scavenging of aerosols, resulting in a net increase in cloud aerosols beyond the original input. This hypothesis hinges on a relative decrease of IFN in polluted air; if IFN were increased then there would be a relative increase of ice water with respect to liquid water, reduced in-cloud production, and increased cloud scavenging of aerosol. 


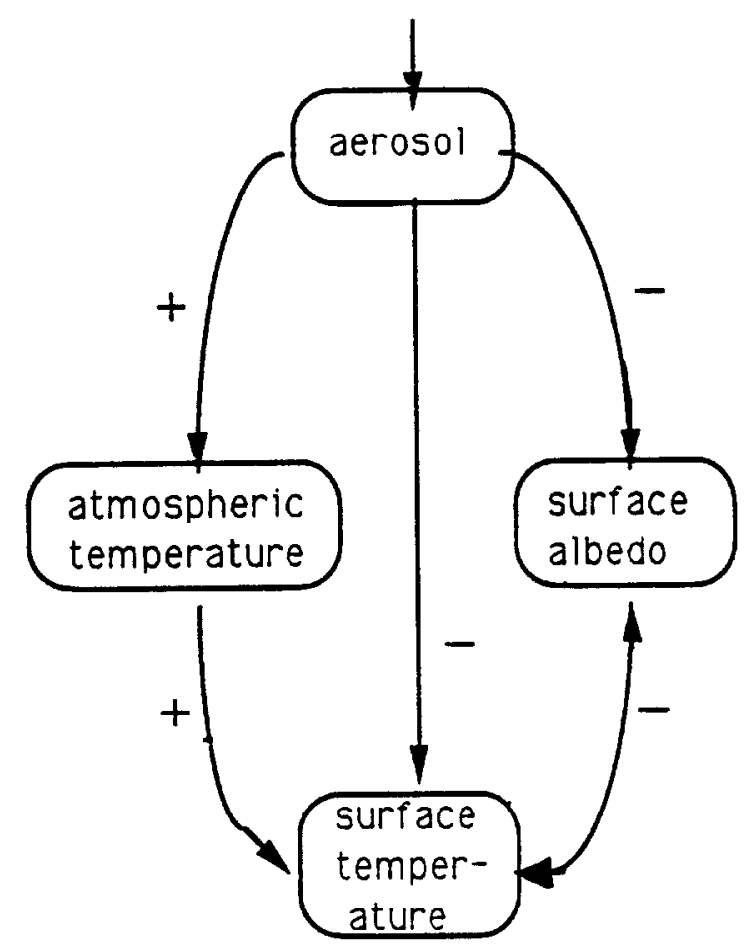

Fig. 2. Schematic diagram of the interactions between clouds and aerosols. The direction of the arrow indicates the direction of the interaction; + indicates a positive interaction (an increase in the first quantity leads to an increase in the second quantity); - indicates a negative interaction (an increase in the first quantity leads to a decrease in the second quantity).

\section{Aerosol-climate interactions}

The impact of aerosols on the Arctic Ocean climate arises from perturbations to the radiative balance. The 'direct' effects of aerosols on the radiative balance arise from the perturbations to the radiative fluxes associated with the absorption and scattering of radiation by the aerosol itself, in contrast to the 'indirect' effects of aerosols on the radiative fluxes, which arise from the impact of aerosols on cloud microphysical properties (see Section 4 on cloud-climate interactions). 'Dry' aerosol, without any water uptake, scatters shortwave solar radiation and the carbonaceous components of the aerosol absorb solar radiation. The dry aerosol particles are too small to interact with the infrared thermal radiation (Shaw and Stamnes, 1980). Blanchet and List (1987) have pointed out the importance of considering water uptake by deliquescent aerosols in determining the radiative effects of aerosols, which may substantially increase the size of the aerosol particles and thus their optical properties. Blanchet found that at high relative humidities, the infrared optical depth of deliquescent aerosols may be as large as the visible optical depth.

Early estimates by Shaw and Stamnes (1980) indicated atmospheric shortwave radiative heating rates as high as $1^{\circ} \mathrm{C} /$ day, due directly to the (dry) arctic pollution aerosol. Porch and MacCracken (1982) found that the haze decreased the solar radiation absorbed at the surface by 10 $\mathrm{W} / \mathbf{m}^{2}$. More recent estimates made by Valero and Ackerman (1986) indicate atmospheric heating rates associated with the aerosol to be between 0.02 and $0.19^{\circ} \mathrm{C} /$ day. At first sight, it would thus appear that direct forcing by the aerosol should heat the atmosphere and cool the surface. Because of the complexity of the vertical temperature and humidity structure in the Arctic and the highly reflective underlying snow/ice surface, the direct radiative response to aerosols can be complex. McCracken et al. (1986) and Emery et al. (1992) have suggested that atmospheric shortwave heating by aerosols can enhance the downwelling infrared radiation received at the surface, and may overcompensate for the depletion of shortwave radiation at the surface. The amount of compensation depends on the vertical distribution of the aerosol, the emissivity of the atmosphere, and the albedo of the surface. Emery et al. (1992) showed that the perturbation to the radiative fluxes depended strongly on the assumptions made about the response of atmospheric humidity to warming. If the relative humidity remains constant, then the surface warms; if the specific humidity remains constant, then the surface cools. Blanchet and List (1987) have further hypothesized that contamination of the arctic snow surface by soot and reduction of snow albedo by an increase in the diffuse radiation component in haze conditions will increase the absorption of solar radiation at the ground and can compensate for the attenuation of incident radiation at the surface from the presence of arctic aerosol (Warren and Wiscombe, 1980). Chylek and Coakely (1973) discussed the effect of surface albedo on 
atmospheric heating by aerosols and showed that a diffusing aerosol layer over a dark surface increases the reflectivity of the system (cooling effect), whereas an absorbing aerosol like soot over a bright snow surface reduces the reflectivity of the surface-atmosphere column (warming effect).

Blanchet $(1989 ; 1990)$ has examined the impact of incorporating the radiative effects of moist arctic aerosols (he did not include the impact of aerosols on cloud properties) into a general circulation climate model. These simulations indicated that the net radiative effects of the moist aerosols were in part balanced by a reduction in the meridional transport of heat, resulting in a marginal increase in lower tropospheric temperatures in the Arctic.

The possibility of feedback between warming ocean temperatures and aerosol concentration was first raised by Charlson et al. (1987). A principal source of sulfate particles and $\mathrm{CCN}$ appears to be the oxidation of dimethylsulfide (DMS), which is emitted by phytoplankton in seawater. Therefore, DMS from the oceans may determine the concentrations and size spectra of cloud droplets. Based on an assumption that DMS emissions increase with increasing ocean temperature, there would be an increase in atmospheric aerosol particles. However, the increase of DMS emissions with increasing ocean temperature is not certain. In the Arctic Ocean, the flux of DMS from the ocean occurs through leads, or 'cracks' in the sea ice. It seems unlikely that there would be substantial DMS feedback in the Arctic Ocean associated with a warming; any warming in the Arctic Ocean is first manifested as a melting of sea ice, and does not substantially raise the temperature of the water in the upper ocean. Also, the factors that most enhance biological productivity in the Arctic Ocean are sunlight and nutrients; incoming sunlight would be depleted by additional aerosols. In summary, it is doubtful that there is any temperature-DMS feedback in the Arctic Ocean; aerosol-sunlight-DMS feedback would be negative.

Clearly, the direct radiative effects of aerosols on the arctic radiation balance are very complex (Fig. 3). The absorption and back-scattering of solar radiation by aerosol have a cooling effect on

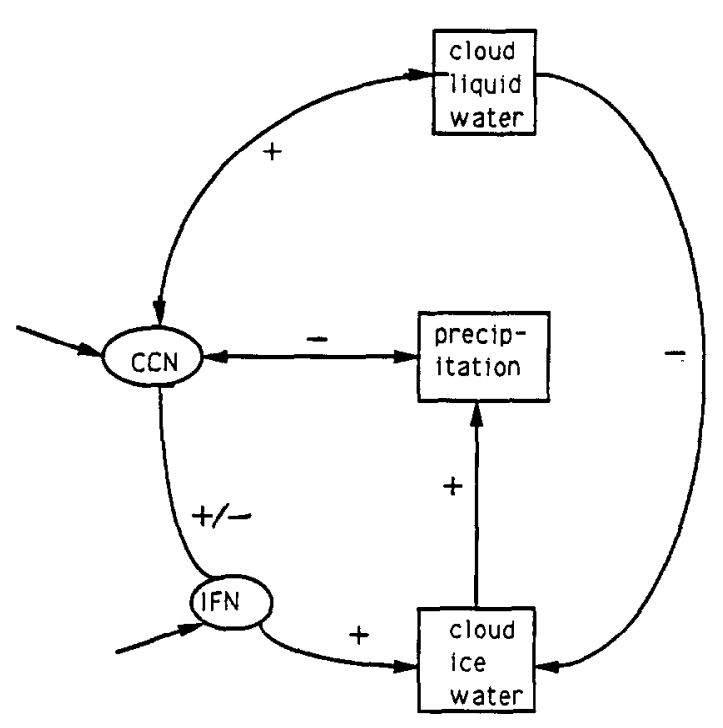

Fig. 3. Schematic diagram of the interactions between aerosols, radiation, and surface temperature. The direction of the arrow indicates the direction of the interaction; + indicates a positive interaction (an increase in the first quantity leads to an increase in the second quantity); - indicates a negative interaction (an increase in the first quantity leads to a decrease in the second quantity).

the surface, which is at least partly countered by the increased diffuse component of shortwave radiation and the decreased surface albedo. The infrared emission at the surface is enhanced by the warmed atmosphere and by infrared emission from deliquescent aerosol, although this warming depends on a fairly high atmospheric relative humidity, as well as advection from lower latitudes. On balance, the net direct perturbation to the surface radiation balance by aerosol is likely to be a small, positive warming. We note here that this is in contrast to the surface cooling expected globally as a result of aerosols. This contrast results from the temperature and humidity inversions and the highly reflective snow/ice surface that characterizes the Arctic Ocean climate.

\section{Cloud-climate interactions}

The impact of clouds on the radiation balance depends on cloud fractional coverage and height, the amount and phase of condensed water, and 
the size and shape of cloud particles. Aerosols modify cloud optical properties by changing the concentration, size, phase, and atmospheric lifetimes of the condensed particles. Increased numbers of $\mathrm{CCN}$ cause a larger number of smaller droplets, rcsulting in an incrcase in cloud optical depth and a decrease in precipitation. All other things remaining constant, smaller droplets result in a decrease in cloud shortwave transmissivity, increases in cloud shortwave reflectivity and absorptivity, and an increase in infrared cloud emissivity. In addition to modifying the condensation process, increased sulfate aerosol concentration may depress droplet freezing by deactivating the ice-forming nuclei, decreasing the temperature of the transition from ice to liquid phase and resulting in a relative enhancement of the liquid phase. If the liquid phase is enhanced relative to the crystalline phase, the size of the particles is reduced and the condensed water content increases as the smaller liquid water particles fall out much more slowly than ice crystals. In view of the static stability of the arctic atmosphere and the persistence particularly of the low-level arctic clouds, the impact of aerosols on cloud microphysical and optical properties may be larger in the Arctic than elsewhere on Earth.

The microphysical properties of summertime clouds over the Arctic Ocean were obtained from aircraft measurements during the June 1980 Arctic Stratus Expcriment (Herman and Curry, 1984; Tsay and Jayaweera, 1984; Curry, 1986). Most of our understanding of the microphysical properties of the wintertime low-level ice crystals over the Arctic Ocean has been obtained from University of Washington flights made in the 1960s (Witte, 1968 ) and the 1980 s as a part of the AGASP program. The microphysical properties of the wintertime lower tropospheric ice crystals have been reviewed by Curry et al. (1990). A summary of what is known about cloud microphysical properties over the Arctic Ocean is given by Curry and Ebert (1992).

The optical properties of the summertime Arctic stratus clouds are described by Herman and Curry (1984), Curry and Herman (1985), and Tsay et al. (1989), using mcasuremcnts obtained from the Arctic Stratus Experiment. The single-scatter- ing properties of the cloud drops (e.g. volume extinction coefficient and single scatter albedo), as well as the cloud bulk radiative properties (i.e. reflectance, transmittance, absorptance, and emittance) were all found to show significant dependence upon the drop size distribution. Larger droplet concentrations and smaller drop sizes result in increased shortwave reflectance and longwave emittance, with decreases in shortwave transmittance. The dependence of shortwave radiative properties on cloud drop size distribution has long been established (Welch et al., 1980), but the dependence of longwave emissivity on drop size distribution is typically ignored (Stephens, 1978), since clouds with a liquid water path exceeding about $30 \mathrm{~g} / \mathrm{m}^{2}$ emit approximately as black bodies. However, Curry and Herman (1985) found that the liquid water path in, arctic stratus was frequently less than $20 \mathrm{~g} / \mathrm{m}^{2}$ even during summer, and in the range where emissivity is sensitive to drop size distribution. Presumably, clouds during the colder seasons would have smaller liquid water paths, showing an even stronger dependence of emittance on drop size distribution.

During the cold half of the year when sunlight is largely absent, temperatures are sufficiently cold throughout the troposphere that the condensate is predominantly crystalline, including condensate near the surface. Lower tropospheric layers of ice crystals exceeding $3 \mathrm{~km}$ in depth in the central Arctic have been reported by Witte (1968); shallower layers with depths typically less than 1 $\mathrm{km}$ were found during springtime (Curry et al., 1990). The microphysical properties of the lower tropospheric ice crystals have been reviewed by Curry et al. (1990).

The temperatures at which ice crystals occur in the Arctic show a wide range, and the association of phase with temperature is complicated by the fact that falling ice crystals may be observed at levels far away from the level at which they were nucleated. From observations reported by Curry et al. (1990) during April 1983 and 1986, it seems that significant ice crystal nucleation routinely occurs at temperatures as high as -15 to $-20^{\circ} \mathrm{C}$. Earlier observations by Witte (1968) described one case with condensate that was predominantly liquid at temperatures as low as $-32^{\circ} \mathrm{C}$ during 
December 1967, and Jayaweera and Ohtake (1973) found very few ice crystals at temperatures above $-20^{\circ} \mathrm{C}$ during September 1971 and April 1972. The recent observations of Curry et al. (1990) show an overall higher phase transition temperature than the earlier measurements, although general conclusions cannot be drawn due to the small number of observations. However it is apparent from these observations that there are substantial variations in the phase transition temperature in the Arctic on time scales of days to decades.

Observations of the radiative properties of arctic clouds during seasons other than summer are sparse, particularly for the wintertime situation with low-level crystalline clouds. Because of the virtual absence of sunlight, the dominant radiative effect of clouds during wintertime is on the longwave radiative fluxes. The only in situ observations of radiative fluxes in wintertime arctic clouds that we are aware of are those reported by Witte (1968) for the 8- to $14-\mu \mathrm{m}$ spectral region. Calculations using the ice crystal concentrations and size spectra observed by Witte (1968) were recently made by Curry et al. (1990), showing perturbations to the infrared surface flux by the clear-sky ice crystal precipitation to be as large as $80 \mathrm{~W} / \mathrm{m}^{2}$. Values of the visible optical depth for the ice crystal layers were determined by Curry et al. (1990) to range from 5 to 21 for wintertime, and from 0.03 to 3 for springtime.

Curry and Ebert (1992) derived the annual cycle of Arctic Ocean cloud optical properties that are required to be consistent with both the outgoing fluxes at the top of the atmosphere, as determined from satellite, and the available determinations of surface fluxes. Existing data on cloud fractional coverage and cloud microphysical properties were utilized. Features of the derived annual cycle of Arctic Ocean cloud optical properties and cloud radiative forcing are summarized as follows:

1. Arctic clouds have a net warming effect on the surface, in contrast to clouds at lower latitudes.

2. The annual cycle of cloud-radiative forcing shows warming at all times except for cooling during a few weeks in mid-summer.

3. Variations in cloud fractional coverage result in variations in the date of the onset of snow melt, which may account for observed interannual variability in the melt season.

4. Low clouds have the greatest impact on the surface radiative flux.

5. During summertime, the net surface radiation flux decreases for both an increase and a decrease in drop size.

6. Surface radiative fluxes vary nonlinearly with cloud fraction, due to changes in surface characteristics.

The sensitivity of the arctic radiation balance to changes in cloud optical properties that could be attributed to aerosols has been examined theoretically by Curry and Ebert $(1990,1992)$ and Curry et al. (1993), using a one-dimensional model of radiative transfer and sea ice thermodynamics (Ebert and Curry 1993). Fig. 4 (Curry et al. 1993) shows the modeled sensitivity of the annual cycle of surface radiation fluxes over the Arctic Ocean to changes in cloud water droplet effective radius $\left(r_{\mathrm{e}}\right)$, which might arise in association with changes in aerosol and $\mathrm{CCN}$ characteristics (note that a decreasing value of $r_{e}$ is hypothesized to result from an increase in $\mathrm{CCN}$ ). The effective radius is defined as the average droplet radius weighted by the droplet cross-sectional area, and is the moment of the drop size distribution that is most directly related to the radiation extinction cross section of the drops. An increasing amount of $\mathrm{CCN}$ would act to reduce the values of $r_{\mathrm{e}}$ for the liquid water clouds.

As seen in Fig. 4a, the incident surface shortwave flux decreases with decreasing values of $r_{\mathrm{e}}$. As drop sizes become smaller, cloud reflectivity increases, reducing the incoming shortwave flux. Examination of Fig. $4 \mathrm{~b}$ shows that the impact of changing $r_{\mathrm{e}}$ is not limited to the shortwave flux, as decreasing values of $r_{\mathrm{e}}$ also result in an increase in downward longwave flux. Since the emissivity of arctic clouds is significantly less than unity (Curry and Herman, 1985), decreasing $r_{\mathrm{e}}$ will increase the infrared optical depth and thus the infrared emissivity. It is noted here that the 

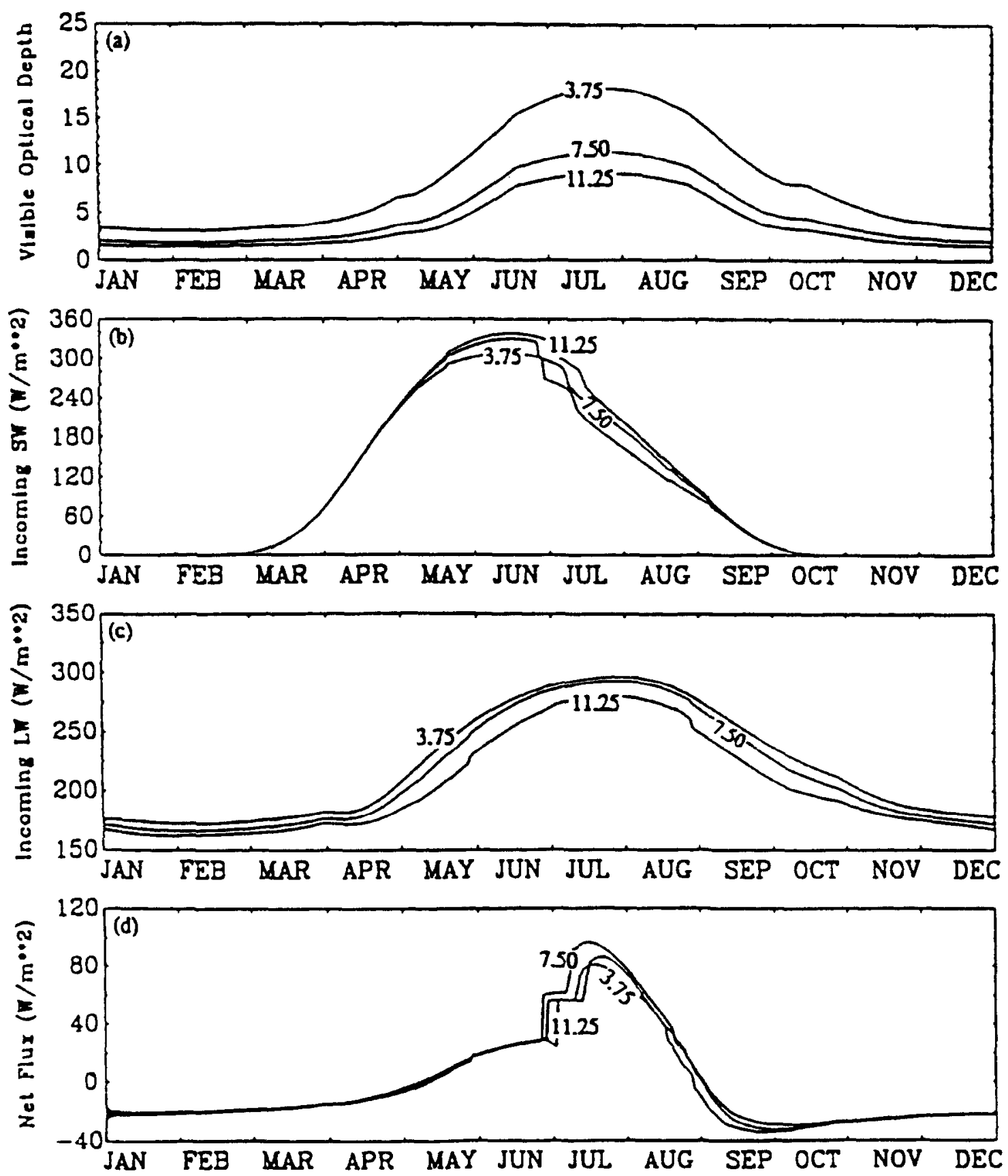

Fig. 4. Sensitivity to water droplet effective radius of: (a) visible optical depth, (b) incoming surface shortwave flux, (c) incoming surface longwave flux, and (d) net surface flux. The labels on the curve $(7.50 \pm 3.75 \mu \mathrm{m})$ correspond to the low cloud drop size. The corresponding mid-cloud drop sizes are $4.70 \pm 2.35 \mu \mathrm{m}$ (after Curry et al., 1993a).

infrared flux of clouds at lower latitudes does not show this sensitivity to $r_{\mathrm{e}}$, since the low-latitude water clouds are typically much more optically thick and emit nearly as black bodies. The effect of changing $r_{\mathrm{e}}$ on the net surface radiative flux (the sum of the net shortwave and longwave 
fluxes) over the Arctic Ocean is seen in Fig. 4c to be complex, with a pronounced annual cycle. During winter, the longwave effects dominate in the absence of solar radiation, whereas the shortwave effects dominate during summer. The nonlinearities of the influence of changing $r_{\mathrm{e}}$ on the net surface radiation seen in Fig. $4 \mathrm{c}$ arise from the sensitivity of the sea ice characteristics (e.g. albedo, temperature) to the surface fluxes.

Curry and Ebert (1990) used a one-dimensional model of radiative transfer and sea ice thermodynamics to examine the sensitivity of sea-ice thickness to changes in the net radiative flux associated with changes in drop size distribution (as represented by $r_{\mathrm{e}}$ ) that might possibly arise from increased pollution. In these experiments, the value of $r_{\mathrm{e}}$ was varied from $13 \mu \mathrm{m}$, which is representative of a stratiform cloud in a remote maritime region, to $5 \mu \mathrm{m}$, representative of highly polluted air. Fig. 5 shows the modeled sensitivity of the annually averaged equilibrium thickness of sea ice to $r_{\mathrm{e}}$. The minimum sea ice thickness is seen to occur for a value of $r_{\mathrm{e}}=8.5 \mu \mathrm{m}$, with the modeled sea ice thickness increasing for values of $r_{\mathrm{e}}$ both greater than and less than $8.5 \mu \mathrm{m}$ [note that the present day value of $r_{\mathrm{e}}$ for liquid water clouds in the Arctic is believed to be 7.5 $\mu \mathrm{m}$ for low-level clouds and $4.7 \mu \mathrm{m}$ for mid-level clouds; see Curry and Ebert (1992)].

This somewhat surprising result is explained by considering the combined effects on the shortwave and longwave fluxes of changing $r_{\mathrm{e}}$. Increasing cloud optical thickness (associated with a decrease in $r_{\mathrm{e}}$ ) results in a decrease in cloud shortwave transmissivity (decreasing the shortwave flux at the surface) and an increase in cloud longwave emissivity (increasing the longwave flux at the surface). Examination of the annual cycle of the radiative fluxes (Fig. 4) shows that the dominant radiative perturbation associated with decreasing $r_{\mathrm{e}}$ occurs during the summer. The shortwave perturbation is dominant at small values of $r_{e}$, since the summertime clouds have a longwave emissivity of nearly unity at the smaller values of $r_{\mathrm{e}}$, whereas the longwave emissivity varies negligibly as $r_{\mathrm{e}}$ decreases. As $r_{\mathrm{e}}$ increases, the surface incoming longwave flux decreases and the shortwave flux increases. As $r_{\mathrm{e}}$ increases, however, the longwave perturbation becomes increasingly im-

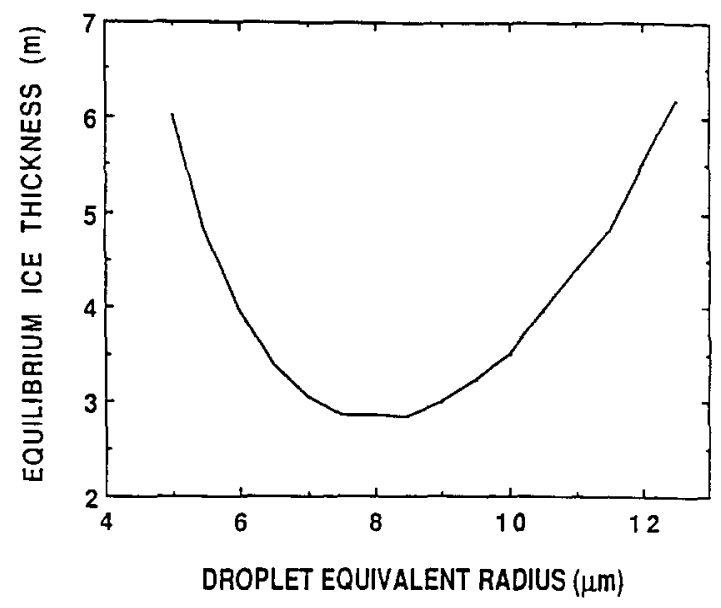

Fig. 5. Modeled sensitivity of the annually averaged equilibrium thickness of sea ice to water droplet effective radius (after Curry and Ebert, 1990).

portant, since the clouds become less opaque, affecting a larger part of the annual cycle than does the shortwave perturbation. The case that is believed to correspond most closely to present-day conditions, $r_{\mathrm{e}}=7.5 \mu \mathrm{m}$, occurs near the minimum equilibrium ice thickness in Fig. 5. Increasing the amounts of pollution aerosol is expected to reduce $r_{\mathrm{e}}$, resulting in a significantly altered surface radiation balance, contributing to the increased thickness of sea ice. Since these calculations were made using a one-dimensional model and sea ice dynamics are thus highly parameterized, the derived sea ice thicknesses under perturbed conditions may not be quantitatively correct. However the principal conclusion, that the surface cools and sea ice thickness increases under conditions of decreased values of $r_{\mathrm{e}}$ associated with increased amounts of $\mathrm{CCN}$, is believed to be robust.

A change in atmospheric temperature associated with increased aerosols could result in further cloud-radiation feedbacks. An increase in condensed water content with increasing temperature has been hypothesized by Somerville and Remer (1984) and Platt and Harshvardhan (1988). Curry et al. (1994) have examined this feedback for the Arctic Ocean and have found it to be a positive feedback, whereby atmospheric warming produces increased condensation in the cloud that increases the cloud optical depth, increasing the 
net surface radiation flux, which warms the surface and the atmosphere. However, the above studies implicitly assume that the atmospheric temperature change occurs in response to a surface temperature change and the corresponding convective coupling between the surface and the atmosphere results in an increase in atmospheric water content. The atmospheric warming associated with atmospheric aerosols may not result in a corresponding increase in atmospheric moisture and condensed water; the opposite is more likely, as the atmosphere is stabilized by the warming initially occurring in the atmosphere rather than at the surface. As atmospheric temperature changes, the fractional cloud cover may change due to changes in atmospheric stability, wind speeds, and advective transports from lower latitudes. Whether fractional cloud cover increases or decreases in a warming environment is not known; an increase in fractional cloud cover would have a warming effect and a decrease in fractional cloud cover would have a cooling effect on the surface (Curry et al., 1994).

The cloud-climate feedback mechanism has been described by Curry et al. (1994) (Fig. 6). A perturbation in the aerosol concentration alters the cloud optical depth and thus the surface radiation flux and the surface temperature. This results in a change in sea ice characteristics (i.e. ice thickness and areal distribution, surface temperature, and surface albedo). These changes in sea ice characteristics, particularly the surface temperature and fraction of open water, modify surface fluxes of radiation and sensible and latent heat, which in turn modify the atmospheric temperature, humidity, and dynamics. Modifications to the atmospheric thermodynamic and dynamic structure modify cloud properties (e.g. fractional cloud coverage, cloud optical depth), which in turn modify the surface radiative fluxes.

The effect of clouds on the net flux of radiation at the Arctic Ocean surface is more complex than elsewhere on the globe, due particularly to the presence of the highly reflective sea ice (and the associated ice-albedo feedback), the absence of solar radiation for a large part of the year, low temperatures and water vapor amounts, and the presence of temperature inversions. Understanding the cloud-climate feedback mechanism, and correctly simulating it, requires understanding the changes in (1) fractional cloud coverage and vertical distribution as the vertical temperature and humidity profiles change, and (2) cloud water content, phase, and particle size as atmospheric temperature and composition change. The largest uncertainty in assessing the cloud-climate feedback mechanism is the change in cloud cover in response to a change in atmospheric temperature. Thus, the sign of the cloud-climate feedback over the Arctic is unknown.

The preceding discussion suggests that the first-order 'indirect' effect of increasing aerosol concentration in the Arctic is a slight surface cooling; this cooling is not as pronounced as that expected at lower latitudes because of the sensitivity of the emissivity of arctic clouds to drop size variations (due to the low water content of these clouds). Higher order effects would be expected as the modified atmospheric radiation balance alters the atmospheric boundary layer structure and cloud characteristics, which further modify the radiation balance and affect the sea ice characteristics.

\section{Conclusions}

The 'direct' radiative effects of aerosols suggest a slight surface warming, whereas our understanding of the first-order 'indirect' radiative effects of aerosols indicate a slight surface cooling. In contrast to the situation for lower latitudes, there is no simple relationship in which an increase in aerosols results in a surface cooling, partially counteracting the effects of greenhouse warming. Several features of the interactions between clouds, aerosols, and climate appear to be more complex in the Arctic than in other parts of the globe:

- The high surface albedo in the Arctic that modulates the direct atmospheric heating associated with aerosols.

- The marked annual cycle of aerosols, associated with the transport of pollution into the Arctic.

- The extreme static stability of the arctic lower troposphere and relative lack of cloud entrain- 


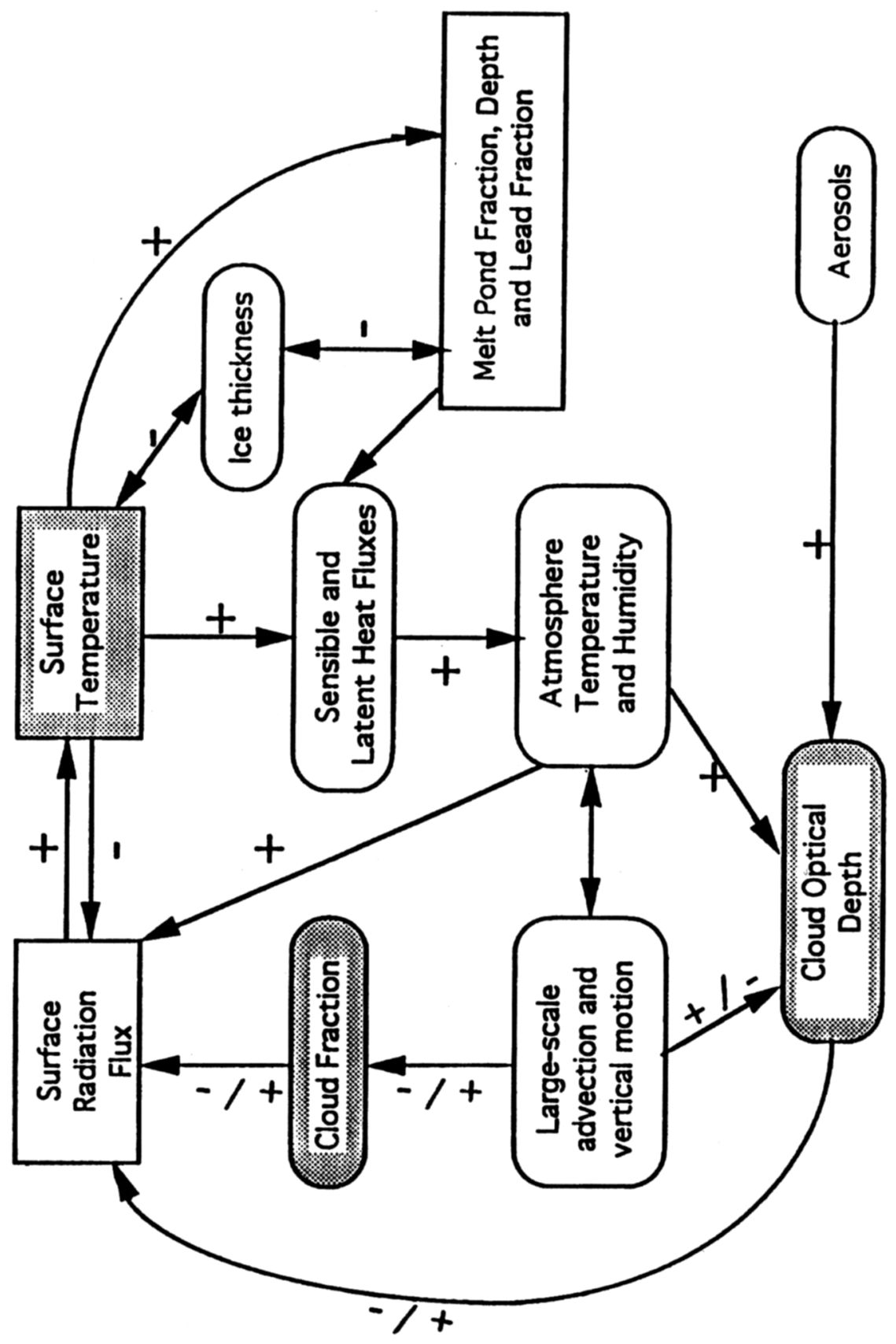

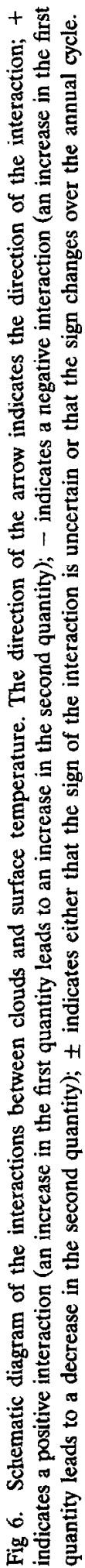


ment that makes the arctic cloud microphysical properties particularly susceptible to modification by aerosols.

- Cloud infrared emissivities that are typically less than unity and thus show a dependence on drop size distribution and aerosol characteristics.

- The complex radiative interactions occurring between aerosols, clouds, and sea ice.

- The role of the annual cycle of arctic aerosol characteristics in clouds, radiative fluxes, and sea ice characteristics.

- Interaction of aerosol radiative effects with atmospheric boundary layer structure and cloud formation processes.

- The annual cycle of aerosol residence time in the Arctic.

- Possible effects of aerosols on ice nucleation and subsequent impact on the hydrology and radiation characteristics of the Arctic.

- Impact of aerosol perturbations on the meridional heat transport to the Arctic.

- Sea ice characteristics that are strongly dependent on the surface radiation fluxes, which are strongly modulated by clouds.

Our understanding of the above physical processes has been hampered by a lack of concurrent measurements of aerosols, clouds, radiation, and sea ice processes; isolated measurements of the individual components of this system cannot be used to elucidate the relevant physical processes or to validate model simulations. Requirements for improving our understanding of aerosol-cloud-climate interactions of the Arctic Ocean include:

- Measurements over the annual cycle that document the impact of aerosol concentration on cloud drop size distributions and cloud optical properties.

- Concurrent measurements of atmospheric temperature, phase of condensate, and concentration and composition of aerosol particles to assess the impact of aerosols on the phase transition between liquid and crystalline cloud particles.
- Improved measurements of atmospheric humidity at cold temperatures to assess the water vapor feedback.

- Measurements and models of the radiative properties of cloud/aerosol mixtures.

- Measurements and models of the interactions among clouds, aerosols, radiation, and boundary layer turbulence that influence the life cycle of low-level boundary layer clouds.

The forthcoming SHEBA (Surface Heat Balance of the Arctic Ocean) Experiment (ARCSS, 1993) will provide such a dataset, so that some of the issues just listed can be addressed.

A true understanding of the interactions among aerosols, clouds, and climate of the Arctic Ocean in a perturbed climate requires global climate models that include interactive aerosols and sea ice. To date, aerosols have been incorporated into general circulation climate models either by specifying an aerosol optical depth or by including advective and turbulent transport and sources and sinks of aerosols. None of the existing climate models includes aerosols in a manner such that they interact with cloud particles and alter both the aerosol and cloud properties. A cloud-aerosol model has not yet been formulated that is suitable for examining the entire suite of interactions among aerosols, clouds, and climate. The few climate models that have included aerosols have focused only on the direct radiative effects of aerosols, whereas the cloud-chemistry models have focused only on the formation of $\mathrm{CCN}$. The resolution of this issue clearly requires an improved observational basis, plus improved climate models that incorporate interactions between clouds and aerosols.

\section{Acknowledgements}

This research was supported by the DOE NIGEC South Central Region.

\section{References}

Albrecht, B.A., 1989. Aerosols, cloud microphysics, and fractional cloudiness. Science, 245: 1227-1230. 
ARCSS, 1993. SHEBA: A Research Program on the Surface Heat Budget of the Arctic Ocean. ARCSS Report 3, available from the ARCSS OAII Science Management Office, Polar Science Center, APL-UW, University of Washington, Seattle, WA 98105-6698.

Barrie, L.A., 1986. Arctic air pollution: an overview of current knowledge. Atmos. Environ., 19: 1995-2010.

Blanchet, J.-P., 1989. Toward estimation of climatic effects due to arctic aerosols. Atmos. Environ., 23: 2609.

Blanchet, J.-P., 1990. The effects of arctic aerosols on a general circulation model simulation: a sensitivity study. In: P.V. Hobbs and M.P. McCormick (Eds.), Aerosols and Climate. A. Deepak Publishing.

Blanchet, J.-P. and R. List, 1987. On radiative effects of anthropogenic aerosol components in Arctic haze and snow. Tellus, 39B: 293-317.

Borys, R.D., 1983. The Effects of Long-range Transport of Air Pollutants on Arctic Cloud-Active Aerosol. Ph.D. Thesis, Colorado State University.

Borys, R.D., 1989. Studies of ice nucleation by arctic aerosol on AGASP-II. J. Atmos. Chem., 9: 169-185.

Chapman, W.L. and J.E. Walsh, 1993. Recent variations of sea ice and air temperature in high latitudes. Bull. Am. Meteorol. Soc., 74: 33-47.

Charlson, R.J., J.E. Lovelock, M.O. Andreae and S.G. Warren, 1987. Oceanic phytoplankton, atmospheric sulfur, cloud albedo and climate. Nature, 326: 655-661.

Charlson, R.J., S.E. Schwartz, J.M. Hales, R.D. Cess, J.A. Coakely, Jr., J.E. Hansen and D.J. Hofmann, 1992. Climate forcing by anthropogenic aerosols. Science, 255: 423-430.

Chylek, P. and J. Coakely, 1973. Man-made aerosol and the heating at atmosphere over polar regions. Proceedings of Twenty-fourth Alaska Science Conference, Fairbanks, AK, pp. $159-160$.

Curry, J.A., 1986. Interactions among turbulence, radiation and microphysics in Arctic stratus clouds. J. Atmos. Sci., 43: 525-538.

Curry, J.A. and E.E. Ebert, 1990. Sensitivity of the thickness of Arctic sea ice to the optical properties of clouds. Ann. Glaciol., 14: 43-46.

Curry, J.A. and E.E. Ebert, 1992. Annual cycle of radiative fluxes over the Arctic Ocean: sensitivity to cloud optical properties. J. Clim., 5: 1267-1280.

Curry, J.A. and G.F. Herman, 1985. Infrared radiative properties of Arctic stratus clouds. J. Clim. Appl. Meteorol., 24: 525-538.

Curry, J.A., F.G. Meyer, L.F. Radke, C.A. Brock and E.E. Ebert, 1990. The occurence and characteristics of lower tropospheric ice crystals in the Arctic. Int. J. Clim., 10: 749-764.

Curry, J.A., E.E. Ebert and J. Schramm, 1993. Impact of clouds on the surface radiation balance of the Arctic Ocean. Meteorol. Atmos. Phys., 57: 197-217.

Curry, J.A., E.E. Ebert and J. Schramm, 1994. Cloud-radiation feedback processes in the Arctic. 8th Conference on Atmo- spheric Radiation, Am. Meteorol. Soc. Nashville TN, January 1994, 76-78.

Curry, J.A., E.E. Ebert and J. Schramm, 1995. On the sea ice albedo climate feedback mechanism. J. Clim., in press.

Dergach, A.L., G.M. Zabrodskiy and V.G. Morachevskiy, 1960. The results of a complex investigation of the type st-sc clouds and fogs in the arctic. Akad. Nauk SSSR Byull. Geofiz., Ser. 1: 66-88.

Ebert, E.E. and J.A. Curry, 1993. An intermediate one-dimensional thermodynamic sea ice model for investigating iceatmosphere interactions. J. Geophys. Res., 98: 10085-10109.

Emery, C.A., R.M. Haberle and T.P. Ackerman, 1992. A one-dimensional modelling study of carbonaceous haze effects on the springtime arctic environment. J. Geophys. Res., 97: 20599-20613.

Hegg, D.A., P.V. Hobbs and L.F. Radke, 1984. Measurements of the scavenging of sulfate and nitrate in clouds. Atmos. Environ., 18: 1939-1946.

Heitzenberg, J., H.-C. Hansson, D.S. Covert, J.-P. Blanchet and J.A. Ogren, 1986. Physical and chemical properties of arctic aerosols and clouds. In: B. Stonehouse (Ed.), Arctic Air Pollution. Cambridge University Press, Cambridge, pp. 25-36.

Herman, G.F. and J.A. Curry, 1984. Observational and theoretical studies of solar radiation in Arctic clouds. J. Clim. Appl. Meteorol., 23: 5-24.

IPCC (Intergovernmental Panel on Climate Change), 1990. Climate Change: The IPCC Scientific Assessment. J.T. Houghton, G.J. Jenkins and J.J. Ephraums (Eds.), Cambridge University Press, New York, 365 pp.

Jayaweera, K.O.L.F. and T. Ohtake, 1973. Concentration of ice crystals in Arctic stratus clouds. J. Res. Atmos., 7: 199-207.

Kahl, J.D., D.J. Charlevoix and N.A. Zaitseva, 1993. Absence of evidence for greenhouse warming over the Arctic Ocean in the past 40 years. Nature, 361: 335-337.

Koptev, A.P. and A.I. Voskresenskii, 1962. On the radiation properties of clouds. The Rand Corporation, Memo RM5003 (translation from original Russian).

Manabe, S., R.J. Stouffer, M.J. Spelman and K. Bryan, 1991. Transient response of a coupled ocean-atmosphere model to gradual changes of atmospheric $\mathrm{CO}_{2}$. Part I: Annual mean response. J. Clim., 4: 785-818.

McCracken, M.C., R.D. Cess and G.L. Potter, 1986. Climatic effects of anthropogenic arctic aerosols: an illustration of climatic feedback mechanisms with one- and two-dimensional climate models. J. Geophys. Res., 91: 14450-14455.

Platt, C.M.R. and Harshvardhan, 1988. Temperature dependence of cirrus extinction: implications for climate feedback. J. Geophys. Res., 93: 11051-11058.

Porch, W.M. and M.C. McCracken, 1982. Parametric study of the effects of arctic soot on solar radiation. Atmos. Environ., 16: 1365-1371.

Radke, L.F. and P.V. Hobbs, 1969. Measurement of cloud condensation nuclei, light scattering coefficient, sodium 
containing particles and Aitken nuclei in the Olympic Mountains of Washington. J. Atmos. Sci., 26: 281-288.

Schlesinger, M.E. and X. Jiang, 1991. A phased-in approach to greenhouse-gas-induced climatic change, EOS, 72: 593.

Shaw, G.E., 1986. Aerosols in Alaskan air masses. J. Atmos. Chem., 4: 157-171.

Shaw, G.E. and K. Stamnes, 1980. Arctic haze: a perturbation of the polar radiation budget. Ann. N.Y. Acad. Sci., 338: 533-539.

Sommervile, R.C. and L.A. Remer, 1984. Cloud optical thickness feedback in the $\mathrm{CO}_{2}$ climate problem. J. Geophys. Res., 89: 9668-9672.

Stephens, G.L., 1978. Radiation profiles in extended water clouds. J. Atmos. Sci., 35: 2111-2222.

Stonehouse, R., (Ed.) 1986. Arctic Air Pollution. Cambridge University Press, Cambridge, 328 pp.

Telford, J.W. and P.B. Wagner, 1981. Observations of condensation growth determined by entity type mixing. Pure Appl. Geophys., 1 19: 934-965.

Tsay, S.-C. and K. Jayaweera, 1984. Physical characteristics of arctic stratus clouds. J. Clim. Appl. Meteorol., 23: 584-596.
Tsay, S.-C., K. Stamnes and K. Jayaweera, 1989. Radiative energy budget in the cloudy and hazy Arctic. J. Atmos. Sci., 46: 1002-1018.

Twomey, S., 1991, Aerosols, clouds and radiation. Atmos. Environ., 25A: 2435.

Valero, F.P.J and T.P. Ackerman, 1986. Arctic haze and the radiation balance. In: B. Stonehouse (Ed.), Arctic Air Pollution. Cambridge University Press, Cambridge, pp. 121-133.

Warren, S.G. and W.J. Wiscombe, 1980. A model for the spectral albedos of snow. II: Effects of aerosols. J. Atmos. Sci., 37: 2734-2750.

Welch, R.M., S.K. Cox and J.M. Davis, 1980. Solar Radiation and Clouds. Meteorological Monographs, 17. American Meteorological Society, $96 \mathrm{pp}$.

Wetherald, R.T. and S. Manabe, 1986. An investigation of cloud cover change in response to thermal forcing. Clim. Change, 8: 5-24.

Witte, H.J., 1968. Airborne Observations of Cloud Particles and Infrared Flux Density in the Arctic. M.Sc. Thesis. Dept. of Atmospheric Sciences, University of Washington. 